Pak. j. sci. ind. res. Ser. A: phys. sci. 2017 60(3)117-121

\title{
Electronic Structure Calculation and Crystal Structure of Trimethylpyridine Cobalt Chloride Complex
}

\author{
Tao Deng \\ School of Mathematics and Computer Science, \\ Northwest Minzu University, Lanzhou 730030, P. R. China \\ (received February 8, 2017; revised August 24, 2017; accepted September 11, 2017)
}

\begin{abstract}
The new complex of 2, 4, 6-trimethylpyridine (TMPy) cobalt chloride consists of $\mathrm{CoCl}_{4}$ anions and trimethylpyridine cations by ionic electrostatic force. This complex belongs in space group of $\mathrm{P} 2{ }_{1} / \mathrm{c}$, having crystalline parameters of $\mathrm{a}=8.915, \mathrm{~b}=17.339, \mathrm{c}=13.945 \AA, \beta=102.54^{\circ}, \mathrm{Z}=4$ and $\mathrm{Dm}=1.37$ $\mathrm{Mg} \cdot \mathrm{m}$. Electronic structure calculation results indicated stronger covalence of $\left(\mathrm{CoCl}_{4}\right)^{2-}$ and demonstrated that the coordination compound of $\mathrm{CoCl}_{4} \cdot(\mathrm{HTMPy})_{2}$ is very stable. There are positive charges on $\mathrm{C}_{2}, \mathrm{C}_{4}$ and $\mathrm{C}_{6}$ positions, and negative charges on $\mathrm{C}_{3}$ and $\mathrm{C}_{5}$ positions in pyridine ring. Mulliken bond grade and atom net charge were derived.
\end{abstract}

Keywords: cobalt complex, trimethylpyridine, crystal structure, electronic structure calculation, Mulliken bond grade

\section{Introduction}

Structure of complexes of Lewis base containing nitrogen with main group elements and transition metals had been widely reported (Xie et al., 2012; Chandrasekhar et al., 2011; MacDonald et al., 2000). In above coordination compounds some ligands did not coordinate to metal atom. It is remarkable that coordination compounds of the cobalt or the nitrogen heterocyclic ring have special structure and extensive application (Deng, 2016; Ma et al., 2008; Song et al., 2006; Horcajada et al., 2006; Kaye and Long, 2005; Zhang, 2005; Seo et al., 2000). In recent studies, complexes of $\mathrm{CoCl}_{2}$ and organic compound containing nitrogen have good catalyst property in polymerization reaction. Although cobalt complexes are often reported in the literature, new materials especially for study of structural determination are needed to search for related rules. In this paper, the new complex of cobalt chloride and 2 , 4, 6-trimethylpyridine (TMPy, Fig. 1) had been synthesized.

The $\mathrm{CoCl}_{4} \cdot(\mathrm{HTMPy})_{2}$ derived at acidic condition was characterized by crystal structure and structural calculation. In this complex, the nitrogen of pyridine ring did not coordinate to cobalt atom. There is 0.00104 positive charge on cobalt atom which bonded to chlorine atoms in strong covalence. Some bond angles of H-C$\mathrm{H}$ groups have been distorted seriously in electrostatic field. In view of the calculation, the complex is very stable.

E-mail: dttom@1zu.edu.cn

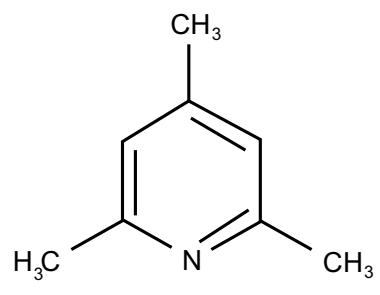

Fig. 1. The structure of 2, 4, 6-trimethylpyridine (TMPy, $\mathrm{C}_{8} \mathrm{H}_{11} \mathrm{~N}$ ).

\section{Materials and Methods}

Preparation and analyses. The complex was prepared by reaction of TMPy and $\mathrm{CoCl}_{2}$ in $2: 1$ molar ratio in 5 $\mathrm{mL}$ water at acidic condition $(\mathrm{pH}=2-3)$, adjusted with $\mathrm{HCl}(0.2 \mathrm{M})$. Good shaped blue needle crystal suited to X-ray diffractometer was derived from this solution evaporating at room temperature about $20{ }^{\circ} \mathrm{C}$ for a week. The density of this crystal was measured by flotation in $\mathrm{CH}_{3} \mathrm{I} / \mathrm{CCl}_{4}$. The cobalt content were estimated by complexometric titration against EDTA and xylenol orange as indicator. The contents of carbon, hydrogen and nitrogen were determined on a Carlo Erba 1106 elemental analyser. Element analysis: found, $\mathrm{Co}=13.28, \mathrm{C}=43.27, \mathrm{H}=5.45, \mathrm{~N}=6.29$; calculation for $\mathrm{C}_{16} \mathrm{H}_{24} \mathrm{Cl}_{4} \mathrm{CoN}_{2}$ : $\mathrm{Co}=13.24, \mathrm{C}=43.17, \mathrm{H}=5.44$, $\mathrm{N}=6.29 \%$.

Data collection. A blue needle single crystal $(0.30 \times$ $0.25 \times 0.20 \mathrm{~mm}$ ) was chosen for data collection using 
an Enraf-Nonius CAD-4 diffractometer. $25 \mathrm{hkl}$ reflections were used to refine the lattice parameters. Details of data collections are reported. Lorentz and polarization correction were applied. Empirical absorption corrections were performed.

Structural analysis and refinement. The structure was determined using direct methods leading to the location of all non-hydrogen atoms. All hydrogen atoms were then evidenced from the difference Fourier map and they were added to the structure factor calculations as fixed at $0.97 \AA$ from their relative attached atoms. Scattering factors for neutral atoms and anomalous dispersion correction for scattering factors were taken from the data, respectively (Cromer and Waber, 1974; Cromer, 1974). Both calculations with PDP-Plus structure determination package and illustrations with ORTEP software were performed on PDP-11 computer (Frenz, 1982).

Electronic structure calculation. Electronic structure of the complex is calculated using the INDO program package on M-340S computer and the data for structure calculation come from the result of X-ray diffraction. The base parameters come from the articles (Ren et al., 1982a; 1982b). This extended INDO is applicable to the electronic structure calculation. The calculation involved the method of selecting the parameters such as the exponents of STO's, the valence orbital ionization potentials, the electron affinity, the electronegativity, the Slater's electrostatic parameters and the bonding parameters etc., and recommended most suitable values for these parameters. The method introduced the formulas required for computer programming including the expressions of rotation matrices, core integrals and the formulas used to ensure the convergence and to annihilated the contamination of spin excited states etc. The detailed method of calculation and the related computer program had been described in these articles (Ren et al., 1982a; 1982b).

\section{Results and Discussion}

According to experimental data of Enraf-Nonius DAD4 diffractometer, the bond lengths and the bond angles presented in Tables 1-2, which showed that the crystal is built up by unit of $\left(\mathrm{CoCl}_{4}\right)^{2-}$ anion and 2, 4, 6trimethylpyridine cation (HTMPy) ${ }^{+}$(Figs. 2-3). The left part in Fig. 2 shows $\mathrm{CoCl}_{4}{ }^{2-}$ in which $\mathrm{Co}^{2+}$ combines with four surrounding $\mathrm{Cl}^{-}$. The right part in Fig. 2 shows (HTMPy) ${ }^{+}$in which the small white balls represent hydrogen atoms. In Fig. 3, the atomic group $\mathrm{CoCl}_{4}{ }^{2-}$
Table 1. Selected bond distances $(\AA)$

\begin{tabular}{llll}
\hline \hline $\mathrm{Co}-\mathrm{Cl}_{1}$ & $2.290(1)$ & $\mathrm{Co}_{1}-\mathrm{Cl}_{2}$ & $2.293(1)$ \\
$\mathrm{Co}-\mathrm{Cl}_{3}$ & $2.237(1)$ & $\mathrm{Co}_{2}-\mathrm{Cl}_{4}$ & $2.245(1)$ \\
$\mathrm{N}_{1}-\mathrm{C}_{1}$ & $1.442(6)$ & $\mathrm{N}_{1}-\mathrm{C}_{5}$ & $1.381(6)$ \\
$\mathrm{N}_{2}-\mathrm{C}_{9}$ & $1.373(5)$ & $\mathrm{N}_{2}-\mathrm{C}_{13}$ & $1.407(5)$ \\
$\mathrm{C}_{1}-\mathrm{C}_{2}$ & $1.363(7)$ & $\mathrm{C}_{1}-\mathrm{C}_{8}$ & $1.475(6)$ \\
$\mathrm{C}_{2}-\mathrm{C}_{3}$ & $1.391(6)$ & $\mathrm{C}_{3}-\mathrm{C}_{4}$ & $1.339(5)$ \\
$\mathrm{C}_{3}-\mathrm{C}_{7}$ & $1.478(6)$ & $\mathrm{C}_{5}-\mathrm{C}_{6}$ & $1.480(6)$ \\
$\mathrm{C}_{9}-\mathrm{C}_{10}$ & $1.345(5)$ & $\mathrm{C}_{9}-\mathrm{C}_{16}$ & $1.482(6)$ \\
$\mathrm{C}_{10}-\mathrm{C}_{11}$ & $1.313(5)$ & $\mathrm{C}_{11}-\mathrm{C}_{12}$ & $1.383(6)$ \\
$\mathrm{C}_{11}-\mathrm{C}_{15}$ & $1.488(6)$ & $\mathrm{C}_{12}-\mathrm{C}_{13}$ & $1.377(6)$ \\
$\mathrm{C}_{13}-\mathrm{C}_{14}$ & $1.481(6)$ & $\mathrm{N}_{1}-\mathrm{H}_{\mathrm{N} 1}$ & $1.054(8)$ \\
\hline \hline
\end{tabular}

Table 2. Selected bond angles $\left({ }^{\circ}\right)$

\begin{tabular}{|c|c|c|c|}
\hline $\mathrm{Cl}_{1}-\mathrm{Co}-\mathrm{Cl}_{2}$ & $108.97(5)$ & $\mathrm{Cl}_{1}-\mathrm{Co}-\mathrm{Cl}_{3}$ & $107.97(5$ \\
\hline $\mathrm{Cl}_{1}-\mathrm{Co}-\mathrm{Cl}_{4}$ & $109.03(5)$ & $\mathrm{Cl}_{2}-\mathrm{Co}-\mathrm{Cl}_{3}$ & $111.16(5)$ \\
\hline $\mathrm{Cl}_{2}-\mathrm{Co}-\mathrm{Cl}_{4}$ & $108.02(5)$ & $\mathrm{C}_{1}-\mathrm{N}_{1}-\mathrm{C}_{6}$ & $119.3(4)$ \\
\hline $\mathrm{C}_{9}-\mathrm{N}_{2}-\mathrm{C}_{13}$ & $120.5(4)$ & $\mathrm{N}_{1}-\mathrm{C}_{1}-\mathrm{C}_{8}$ & $119.2(4)$ \\
\hline $\mathrm{N}_{1}-\mathrm{C}_{1}-\mathrm{C}_{2}$ & $118.8(5)$ & $\mathrm{C}_{1}-\mathrm{C}_{2}-\mathrm{C}_{3}$ & $120.3(4)$ \\
\hline $\mathrm{C}_{2}-\mathrm{C}_{1}-\mathrm{C}_{8}$ & $122.0(4)$ & $\mathrm{C}_{2}-\mathrm{C}_{3}-\mathrm{C}_{4}$ & $118.5(4)$ \\
\hline $\mathrm{C}_{2}-\mathrm{C}_{3}-\mathrm{C}_{7}$ & $122.9(4)$ & $\mathrm{C}_{3}-\mathrm{C}_{4}-\mathrm{C}_{5}$ & $124.3(4$ \\
\hline $\mathrm{N}_{1}-\mathrm{C}_{5}-\mathrm{C}_{4}$ & $119.0(4)$ & $\mathrm{N}_{1}-\mathrm{C}_{5}-\mathrm{C}_{6}$ & $122.9(4$ \\
\hline $\mathrm{C}_{4}-\mathrm{C}_{5}-\mathrm{C}_{6}$ & 118.1(5) & & \\
\hline $\mathrm{H}_{6^{\prime}}-\mathrm{C}_{6}-\mathrm{H}_{6}$ & $104.1(8)$ & $\mathrm{H}_{14}-\mathrm{C}_{14}-\mathrm{H}_{14 "}$ & $94.3(7$ \\
\hline $\mathrm{H}_{6^{\prime}}-\mathrm{C}_{6}-\mathrm{H}_{6^{\prime \prime}}$ & $90.4(7)$ & $\mathrm{H}_{14}-\mathrm{C}_{14}-\mathrm{H}_{14 "}$ & $126.3(7$ \\
\hline $\mathrm{H}_{6}-\mathrm{C}_{6}-\mathrm{H}_{6^{\prime \prime}}$ & $84.4(6)$ & $\mathrm{H}_{14^{\prime \prime}}-\mathrm{C}_{14-\mathrm{H}_{14^{\prime \prime}}}$ & $101.3(7$ \\
\hline $\mathrm{H}_{7^{\prime}}-\mathrm{C}_{7^{-}}-\mathrm{H}_{7^{\prime \prime}}$ & $119.7(9)$ & $\mathrm{H}_{15}-\mathrm{C}_{15}-\mathrm{H}_{15}$ & $106.7(6$ \\
\hline $\mathrm{H}_{7}-\mathrm{C}_{7}-\mathrm{H}_{7}$ & $94.3(7)$ & $\mathrm{H}_{15}-\mathrm{C}_{15}-\mathrm{H}_{15}$ & $64.1(5$ \\
\hline $\mathrm{H}_{7{ }^{\prime \prime}}-\mathrm{C}_{7}-\mathrm{H}_{7}$ & $112(1)$ & $\mathrm{H1}_{5^{\prime}}-\mathrm{C}_{15}-\mathrm{H}_{15^{\prime \prime}}$ & $128.3(7$ \\
\hline $\mathrm{H}_{8^{-}}-\mathrm{C}_{8}-\mathrm{H}_{8}$ & $67.1(7)$ & $\mathrm{H}_{16}-\mathrm{C}_{16}-\mathrm{H}_{16}$ & $97.8(9$ \\
\hline $\mathrm{H}_{8 \mathrm{n}}-\mathrm{C}_{8}-\mathrm{H}_{8}$ & $100.1(6)$ & $\mathrm{H}_{16}-\mathrm{C}_{16}-\mathrm{H}$ & 88.018 \\
\hline $\mathrm{H}_{8^{\prime}}-\mathrm{C}_{8^{-}}-\mathrm{H}_{8^{\prime \prime}}$ & $103(2)$ & $\mathrm{H}_{16^{\prime \prime}}-\mathrm{C}_{16}-\mathrm{H}_{16}$ & $99.3(8$ \\
\hline
\end{tabular}

has the simpler structure, in which $\mathrm{Co}^{2+}$ combines with four surrounding $\mathrm{Cl}^{-}$and the length of four covalent bond are different; the atomic group (HTMPy) ${ }^{+}$, on the other hand, has more complex structure in which smaller balls indicate hydrogen atomics. The data collections are collected in Tables 3-4. The different positions of atoms and bonds are numbered in Fig. 4. The atom net charges and Mulliken bond grade of coordination compound derived from calculation are tabulated in Tables 5-6. The cobalt atom is in the middle of a "square" constituted with the four chlorine atoms $[\mathrm{Co}-\mathrm{Cl}$ from shorter of 2.237(1) $\AA$ to longer of 2.290(1) $\AA$ ]. The interaction distances in the trimethylpyridine are not constituted with bond lengths in a conjugated ring (1.389 $\geqq d \geqq 1.352 \AA$ ) (Busnot et al., 1983). The electrons are divided into two types: $\alpha$ and $\beta$, according to their different spinning directions. The results indicated 


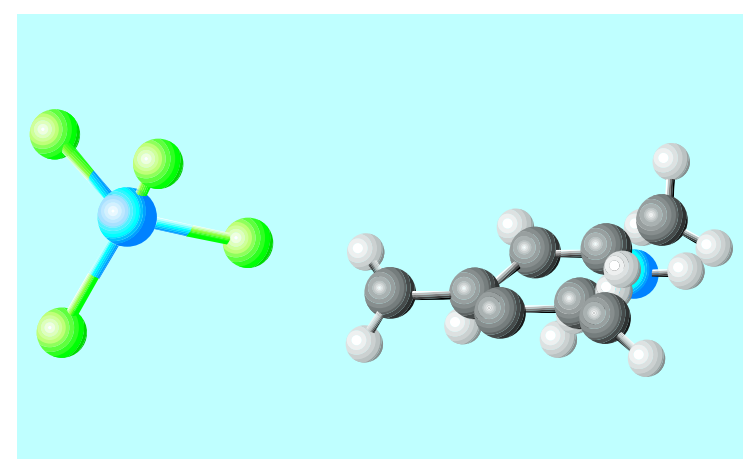

Fig. 2. The anion of $\left(\mathrm{CoCl}_{4}\right)^{2-}$ and the cation of (HTMPy) $)^{+}$.

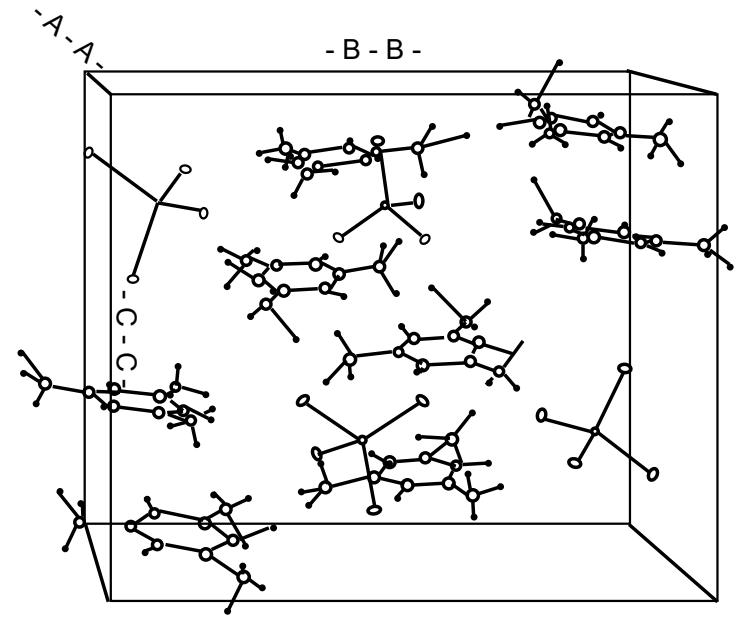

Fig. 3. The crystal structure of complex $\left[\mathrm{CoCl}_{4} \cdot(\mathrm{HTMPy})_{2}\right]$.

electron energy limits to -0.42607-0.19920 Hartree for $\alpha$-electron and $-0.43547-0.19883$ for $\beta$-electron, and electron energy limits of calculation to-2.23361-0.4842 Hartree for $\alpha$-electron and $-2.26333-0.49103$ Hartree for $\beta$-electron. In view of calculation result, the atom net charges are $-0.2066--0.2741$, av. -0.2484 for chlorine atoms and +0.00104 for cobalt, although the cobalt atom is +2 of valence, therefore, the anion of $\left(\mathrm{CoCl}_{4}\right)^{2-}$ is bound through strong covalence. There are negative charges on nitrogen atoms, $\mathrm{C}_{2}$ and $\mathrm{C}_{4}$, and positive charges on $\mathrm{C}_{1}, \mathrm{C}_{3}$ and $\mathrm{C}_{5}$, showing no difference with which have been known that electrophilic substitution reaction (e.g. acylation) often occurs on o-position, and nucleophilic substitution reaction (e.g. alkanisation) often occurs on $p$ - and $m$-positions in aromatic ring. The substituted methyl groups of trimethylpyridine ring
Table 3. Physical properties and parameters for data collection and refinement

\begin{tabular}{ll}
\hline \hline Formula & $\mathrm{C}_{16} \mathrm{H}_{24} \mathrm{Cl}_{4} \mathrm{CoN}_{2}$ \\
Mol. Wt. & 445.1 \\
Space group & $\mathrm{P} 2_{1 / \mathrm{c}}$ \\
$\mathrm{a}(\AA)$ & 8.915 \\
$\mathrm{~b}(\AA)$ & 17.339 \\
$\mathrm{c}(\AA)$ & 13.945 \\
$\beta(\mathrm{deg})$ & 102.54 \\
$\mathrm{~V}\left(\AA^{3}\right)$ & 2104.1 \\
$\mathrm{Z}$ & 4 \\
$\mathrm{Dx}$ & $1.386 \mathrm{Mg} \cdot \mathrm{m}^{-3}$ \\
Dm & $1.37 \mathrm{Mg} \cdot \mathrm{m}^{-3}$ \\
$\mathrm{~F}(000)$ & 456.03 \\
$\mu(\mathrm{Cu}$ K $\left.\alpha)(\mathrm{cm})^{-1}\right)$ & 115.08 \\
$\lambda$ & $1.54184 \AA$ \\
Scan type & $\theta / 2 \theta$ \\
Scan width & $0.5+0.35 \mathrm{tan} \theta$ \\
No. of reflection measured & 3380 \\
No. of observed reflection & 2505 \\
No. of variable, NV & 208 \\
$\mathrm{R}$ & 0.067 \\
Rw & 0.101 \\
\hline \hline
\end{tabular}

Table 4. Fractional atomic coordinates and equivalent isotropic thermal parameter $\left(\AA^{2}\right)$

\begin{tabular}{lllll}
\hline \hline Atom & $\mathrm{x}$ & $\mathrm{y}$ & $\mathrm{z}$ & $\mathrm{Ueq}$ \\
\hline $\mathrm{Co}$ & $0.24324(1)$ & $0.08741(6)$ & $0.23538(7)$ & $2.54(2)$ \\
$\mathrm{Cl}_{1}$ & $0.33706(2)$ & $0.05079(1)$ & $0.39489(1)$ & $3.96(4)$ \\
$\mathrm{Cl}_{2}$ & $0.17724(2)$ & $-0.02073(1)$ & $0.14096(1)$ & $3.83(4)$ \\
$\mathrm{Cl}_{3}$ & $0.03584(2)$ & $0.16215(1)$ & $0.23289(2)$ & $4.86(5)$ \\
$\mathrm{Cl}_{4}$ & $0.42873(2)$ & $0.14923(1)$ & $0.17994(2)$ & $4.81(2)$ \\
$\mathrm{N}_{1}$ & $0.30086(7)$ & $0.29179(5)$ & $0.42654(5)$ & $5.4(2)$ \\
$\mathrm{N}_{2}$ & $0.22353(8)$ & $0.35656(4)$ & $0.15402(5)$ & $4.9(2)$ \\
$\mathrm{C}_{1}$ & $0.43141(8)$ & $0.33373(4)$ & $0.41228(5)$ & $3.4(1)$ \\
$\mathrm{C}_{2}$ & $0.42065(8)$ & $0.41189(4)$ & $0.40244(5)$ & $3.5(2)$ \\
$\mathrm{C}_{3}$ & $0.28320(8)$ & $0.44923(4)$ & $0.40411(4)$ & $2.7(1)$ \\
$\mathrm{C}_{4}$ & $0.16425(6)$ & $0.40704(3)$ & $0.41845(4)$ & $1.6(1)$ \\
$\mathrm{C}_{5}$ & $0.16700(7)$ & $0.33109(4)$ & $0.42894(5)$ & $3.3(2)$ \\
$\mathrm{C}_{6}$ & $0.02739(9)$ & $0.29255(5)$ & $0.44658(6)$ & $4.8(2)$ \\
$\mathrm{C}_{7}$ & $0.26450(1)$ & $0.53377(4)$ & $0.39469(5)$ & $4.4(2)$ \\
$\mathrm{C}_{8}$ & $0.57601(9)$ & $0.29207(6)$ & $0.41316(8)$ & $6.7(3)$ \\
$\mathrm{H}_{\mathrm{N} 1}$ & 0.27734 & 0.23242 & 0.41602 & $4^{*}$ \\
$\mathrm{H}_{\mathrm{N} 2}$ & 0.22070 & 0.29883 & 0.16602 & $4^{*}$ \\
\hline \hline
\end{tabular}

being in electrostatic field are seriously distorted, compared with that in coordination field. All eighteen $\mathrm{H}-\mathrm{C}-\mathrm{H}$ bond angles have been changed obviously except that on $\mathrm{C}_{7}\left(\right.$ av. $\left.108.6^{\circ}\right)$ and $\mathrm{C}_{14}\left(\right.$ av. $\left.107.3^{\circ}\right)$ being similar to classical tetrahedral angle. Considering the energy in this system of complex, the electronic energy (EE) is -1379.6929 Hartree, and the nuclear energy is 
+1167.7988 Hartree, so that the total energy (TE) is 211.8941 Hartree, which indicated that the ionic complex is very stable. $\mathrm{CoCl}_{4}{ }^{2-}$ coordinate ion often occurs in

Table 5. Some atom net charges of coordination compound

\begin{tabular}{llllllll}
\hline \hline $\mathrm{Co}$ & 0.00104 & $\mathrm{C}_{1}$ & 0.2494 & $\mathrm{C}_{8}$ & -0.1351 & $\mathrm{C}_{15}$ & -0.0884 \\
$\mathrm{C}_{1}$ & -0.2564 & $\mathrm{C}_{2}$ & -0.1111 & $\mathrm{C}_{9}$ & 0.2489 & $\mathrm{C}_{16}$ & -0.1214 \\
$\mathrm{C}_{2}$ & -0.2066 & $\mathrm{C}_{3}$ & 0.1826 & $\mathrm{C}_{10}$ & -0.1496 & $\mathrm{H}_{\mathrm{N} 1}$ & 0.1802 \\
$\mathrm{C}_{3}$ & -0.2741 & $\mathrm{C}_{4}$ & -0.1205 & $\mathrm{C}_{11}$ & 0.2067 & $\mathrm{H}_{\mathrm{N} 2}$ & 0.1563 \\
$\mathrm{C}_{4}$ & -0.2585 & $\mathrm{C}_{5}$ & 0.2509 & $\mathrm{C}_{12}$ & -0.1111 & $\mathrm{H}_{2}$ & 0.0443 \\
$\mathrm{~N}_{1}$ & -0.05846 & $\mathrm{C}_{6}$ & -0.0489 & $\mathrm{C}_{13}$ & 0.2189 & $\mathrm{H}_{4}$ & 0.0561 \\
$\mathrm{~N}_{2}$ & -0.05724 & $\mathrm{C}_{7}$ & -0.0800 & $\mathrm{C}_{14}$ & -0.0890 & & \\
\hline \hline
\end{tabular}

Table 6. The Mulliken bond grades of coordination compound

\begin{tabular}{llllllll}
\hline \hline 1 & 0.6375 & 13 & 1.0780 & 25 & 0.7273 & 37 & 0.7546 \\
2 & 0.6477 & 14 & 1.0070 & 26 & 1.0016 & 38 & 0.8142 \\
3 & 0.6615 & 15 & 0.8550 & 27 & 0.8018 & 39 & 0.5028 \\
4 & 0.6609 & 16 & 0.6668 & 28 & 0.8735 & 40 & 0.7448 \\
5 & 0.6529 & 17 & 0.6196 & 29 & 0.8215 & 41 & 0.7953 \\
6 & 0.8451 & 18 & 0.5878 & 30 & 0.7004 & 42 & 0.7034 \\
7 & 1.0612 & 19 & 0.8218 & 31 & 1.0617 & 43 & 0.8320 \\
8 & 0.8054 & 20 & 0.8751 & 32 & 0.8300 & 44 & 1.0023 \\
9 & 0.8007 & 21 & 0.5640 & 33 & 1.1007 & 45 & 0.8168 \\
10 & 0.7225 & 22 & 0.7506 & 34 & 0.8689 & 46 & 0.8022 \\
11 & 1.1061 & 23 & 0.8116 & 35 & 0.6246 & - & - \\
12 & 0.8852 & 24 & 1.0826 & 36 & 0.8546 & - & - \\
\hline \hline
\end{tabular}

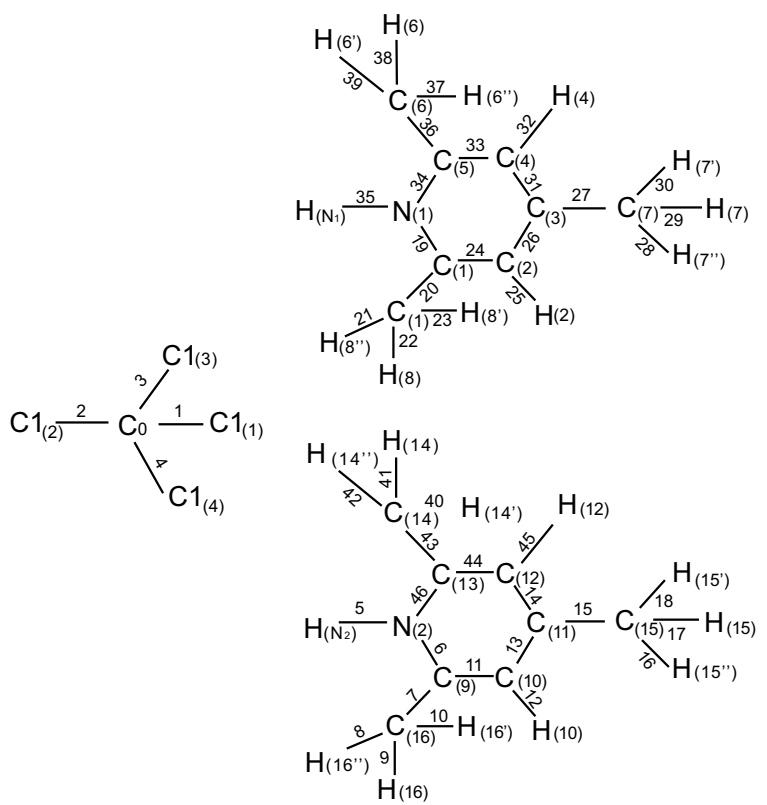

Fig. 4. The numerical atoms and bonds of complex complex containing $\mathrm{Co}^{2+}$ and $\mathrm{Cl}^{-}$due to stable coordinate bond, such as several complexes (Guo et al. 2015) having $\mathrm{CoCl}_{4}{ }^{2-}$ by combining cobalt dichloride and pyridine bisoxazoline. The anionic part can be described as distorted tetrahedron. Bond length of cobalt ion and four surrounding $\mathrm{Cl}^{-}$are not the same, the shortest is $2.2520 \AA$ and the longest is $2.2983 \AA$, and such is the case with the result in this paper.

\section{Acknowledgement}

The author is very grateful for financial support of National Natural Science Foundation of China (No. 31560256).

\section{References}

Busnot, A., Busnot, F., Leclaire, A., Bernard, M. 1983. Structure of diacetatiobis (2, 4, 6-trimethyl pyridine) copper(II). Zeitschrift für Anorganische und Allgemeine Chemie, 503: 207-212.

Cromer, D.T. 1974. International Tables for X-ray Crystallography, vol. IV, Table 2.3.1. UK.

Cromer, D.T., Waber, J.T. 1974. International Tables for X-ray Crystallography, vol. IV, Table 2.2.B. Kynoch Press, Birmingham, UK.

Chandrasekhar, V., Thirumoorthi, R., Metre, R.K., Mahanti, B. 2011. Journal of Organometallic Chemistry, 696: 600-606.

Deng, T. 2016. Study on Schiff bases derived from sulfathiazole and sulfamethoxypyridazine. Journal of the Chemical Society of Pakistan, 18: 133-138.

Frenz, B. A. 1982. Enraf-Nonius Structure Determination Package, CAD-4, SDP-Plus, Version 1.0, College Station, Texas, USA.

Guo, J., Wang, B.L., Bi J.F., Zhang, C.Y., Zhang, H.X., Bai, C.X., Hu, Y.M., Zhang, X. Q. 2015. Synthesis, characterization and 1,3-butadiene polymerization studies of cobalt dichloride complexes hearing pyridine bisoxazoline ligands. Polymer, 59: 124132.

Horcajada, P., Serre, C., Vallet-Regi, M., Sebban, M., Taulelle, F., Férey, G. 2006. Met-organic framework as efficient materials for drug delivery. Angewandte Chemie, International Edition, 45: 5974-5978.

Kaye, S.S., Long, J.R. 2005. Hydrogen storage in the dehydrated Prussian blue analogues $\mathrm{M}_{3}\left[\mathrm{Co}(\mathrm{CN})_{6}\right]_{2}$ $(\mathrm{M}=\mathrm{Mn}, \mathrm{Fe}, \mathrm{Co}, \mathrm{Ni}, \mathrm{Cu}, \mathrm{Zu})$. Journal of the American Chemical Society, 127: 6506-6507.

Ma, S., Sun, D., Simmons, J.M., Collier, C.D., Yuan, D., Zhou, H.C. 2008. Metal-organic framework 
from an anthracene derivative containing nanoscopic cages exhibiting high methane uptake. Journal of the American Chemical Society, 130: 1012-1016. MacDonald, J.C., Dorrestein, P.C., Pilley, M.M., Foote, M.M., Lundberg J.L., Henning, R. W. 2000. Design of layered crystalline materials using coordination chemistry and hydrogen bonds. Journal of the American Chemical Society, 122: 11692-11702.

Ren, J.Q., Li, L.M., Wang, X.Z., Hsu, K.S. 1982a. The INDO method applicable to the electronic structure calculation of lanthanide compounds. I. The formulas required for computer programming. Acta Scientiarum Naturalium Universitatis Pekinensis, 28: 30-48.

Ren, J.Q., Li, L.M., Wang, X.Z., Hsu, K.S. 1982b. The INDO method applicable to the electronic structure calculation of lanthanide compounds.II. The selection of parameters and the computer program. Acta Scientiarum Naturalium Universitatis
Pekinensis, 28: 49-62.

Seo, J.S., Whang, D., Lee, H., Jun, S.I., Oh, J., Jeon, Y.J., Kim, K. 2000. A homochiral metal-organic porous materials for enantioselective separation and catalysis. Nature, 404: 982-986.

Song, Y.M., Yao, X.Q., Deng, T., Wu J.X., Wu, Q. 2006. Structure of tetrakis(pyridinioacetate) neodymium (III) tetrahydrate perchlorate. Chemical Papers, 60: 302-305.

Xie, Z.L., Xie, Y.R., Xu, G.H., Du, Z.Y., Zhou, Z.G., Lai, W.L. 2012. Four novel alkaline-earth metal coordination polymers with networks controlled by the diverse coordination modes of aminosulfonated ligand: Synthesis, crystal structures and luminescent properties. Inorganica Chimica Acta, 384: $117-124$.

Zhang, X.M. 2005. Hydro(solvo)thermal in situ ligand syntheses. Coordination Chemistry Reviews, 249: 1201-1219. 